\section{AB0408 ANALYSIS OF THE CORRELATION OF COMPOSITE INDICATORS OF ACTIVITY OF THE DISEASE AND THE CONCORDANCE BETWEEN THE DIFFERENT STATES OF ACTIVITY IN PATIENTS WITH RHEUMATOID ARTHRITIS}

T. fontana, B. ferreira althoff, C. janson ferreira, Y. alfaro, G. ricardo werner de castro, I. alves pereira. Rodovia Antonio Luis de Moura Gonzaga, Unisul Pedra Branca, Florianópolis, Brazil

Background: Rheumatoid arthritis (RA) is an inflammatory joint disease of systemic involvement and varied evolution, which uses different disease evaluation scores. It is essential that these instruments be evaluated according to the disease, so that the treatment algorithms can be applied independently.

Objectives: To analyse a correlation of disease activity indexes (ICADs) and a concordance between different states of activity in patients with Rheumatoid Arthritis.

Methods: Cross-sectional study based on 100 patients of outpatient care from a multicenter prospective cohort study. Approved by CEP UNISUL. Statistical analysis by the SPSS 18.0 program, using the Pearson Correlation Coefficient and McNemar-Bowker Concordance, considering significance level $p<0,05$.

Results: Majority female patients (86\%), with an average age of 54 years, who were active in their jobs (53\%) and had a positive rheumatoid factor in $65 \%$. The average values of the ICADs were DAS-28 (3.6), DAS-28 PCR (3.0), SDAI (13.4), CDAI (12.5) and RADAI (3.5), respectively. Many were classified with moderate disease activity of the disease. The degree of correlation was very strong $(>0.8)$ and strong (between 0.8 and 0.6 ) in most ICADs and a concordance of remission DAS-28PCR ranged from $41.3 \%$ to $54.3 \%$ with the other ICADs.

Conclusions: The ICADs presented a strong correlation with each other, as well a level of similarities in the classification of the different degrees of activity. These results confirm that in different patients with $\mathrm{RA}$, the ICADs serve to define active disease and to aid in the treatment strategy, so it is not imperative to use only a single evaluation score.

\section{REFERENCES:}

[1] Alvaro PM, Laiz A. Is DAS a Profitable Score to Be Used for Rheumatoid Arthritis Patient Follow Up? Reumatología Clínica (English Edition) 2011;7 (5):336-8.

[2] Medeiros MMC, Oliveira BMGB, Cerqueira JVM, Quixadá RTS, Oliveira IMX. Correlação dos índices de atividade da artrite reumatoide (DAS-28 VHS, DAS28-PCR, SDAI, CDAI) e concordância dos estados de atividade da doença com vários pontos de corte numa população do nordeste brasileiro. Rev Bras Reumatol 2015;55(6):477-84.

[3] Gaujoux-Viala C, Mouterde G, Baillet A, Claudepierre P, Fautrel B, Le Loët $\mathrm{X}$, Maillefert JF. Evaluating disease activity in rheumatoid arthritis: Which composite index is best? A systematic literature analysis of studies comparing the psychometric properties of the DAS, DAS28, SDAI and CDAl. Joint Bone Spine 2012;79(2):149-55

Disclosure of Interest: None declared

DOI: 10.1136/annrheumdis-2018-eular.3677

\section{AB0409 MISSING THE BIG PICTURE? AN AUDIT OF HAND X- RAYS IN BIOLOGIC TREATED RHEUMATOID ARTHRITIS PATIENTS}

U. Habib ${ }^{1}$, A. Sahni ${ }^{1}$, M. Lloyd ${ }^{1}$, B. Barber ${ }^{2}$, J. Cameron ${ }^{1}$, S. Melath ${ }^{1}$, D. Christidis ${ }^{1}$, J. Wajed ${ }^{1}$, A. Mistlin ${ }^{1}$, S. Cooper ${ }^{1} .{ }^{1}$ Rheumatology, ${ }^{2}$ Radiology, Frimley Park Hospital, Frimley, UK

Background: Rheumatoid arthritis (RA) treatment is target driven. The aim is to prevent joint damage and relieve pain and functional loss. $X$-ray $(X R)$ erosions are an unambiguous sign of disease activity and progression.

Objectives: We aimed to review our practice in looking for erosions in our biologic treated patients. We chose this group as they were likely to have the most severe and clearly defined RA.

Methods: 100 random biologic treated patients from our biologics database were selected for analysis. We used patient letters and our digital imaging system (PACS) for further information. Our PACS has records running back to 2004.

Results: Mean age was 58 years. $77 \%$ were female. Mean duration of RA was 10.6 years (range $0.9-44$ years). 46 were currently receiving etanercept; 17 tocilizumab; 15 adalimumab; 14 certolizumab; 5 rituximab and 3 abatacept. 61 patients were current prednisolone users. The mean duration of biologic treatment was 4.8 years. 44 patients had received more than one biologic drug; 17 more than two. Mean DAS was 3.4. 72 patients had had previous documented hand XRs; 25 (34\%) of these had erosions. The mean duration since the last hand XR was 37 months. 27 patients had had 2 previous hand XRs; 11 had had 3,4 had had 4 and 2 had had 6 previous XRs. In 19 cases hand erosions appeared to have progressed in the patients who had had more than one XR. 44 patients had had previous foot XRs; 15 (34\%) had erosions. 26 patients had had more than one foot XR. 36 patients had had previous joint ultrasound (US); in $17(47 \%)$ US suggested active synovitis. The mean duration since the last US was 17 months.

Conclusions: Our patients had relatively high disease activity despite biologic treatment, over half were also on steroids and significant numbers had had several biologic switches. Despite this only around two thirds of patients had had previous hand XRs documented over an average of 10 years RA duration, and there was a long average time since the last imaging. US rates were lower, but scans were more recent, perhaps suggesting a more modern trend to US over XR. Less than half of patients had had foot XRs. Although there was a lower rate of foot XRs the rate of erosions was similar in hand and foot XRs, suggesting similar patterns of joint damage. Interestingly, despite erosions being a hard end point in most treatment trials, NICE guidance only suggests XR early in RA in 'people with persistent synovitis'1 and EULAR guidance suggests assessing for 'structural damage' without specifying time intervals. ${ }^{2}$ Although newer imaging techniques may be more sensitive, XRs remain cheap, quickly accessible and allow objective assessment, particularly in long term patients being assessed for biologic switches. Our audit suggests that this well established and useful measure of disease burden may currently be relatively neglected.

\section{REFERENCES}

[1] https://www.nice.org.uk/guidance/qs33

[2] http://ard.bmj.com/content/early/2017/03/17/annrheumdis-2016-210715

Disclosure of Interest: None declared

DOI: 10.1136/annrheumdis-2018-eular.4084

\section{$\mathrm{AB} 0410$ DIAGNOSIS OF LUNG DISEASE ASSOCIATED WITH RHEUMATOID ARTHRITIS, A PROSPECTIVE MONOCENTRIC STUDY}

V. Huber Somme ${ }^{1}$, S. Hirschi ${ }^{2}$, M. Ohana ${ }^{3}$, R. Felten ${ }^{1}$, E. Chatelus ${ }^{1}$, R.-M. Javier ${ }^{1}$, C. Sordet ${ }^{1}$, L. Arnaud ${ }^{1}$, J. Sibilia ${ }^{1}$, J.-E. Gottenberg ${ }^{1}$, H. Petit ${ }^{1}{ }^{1}$ Rheumatology; ${ }^{2}$ Pulmonology; ${ }^{3}$ Radiology, Strasbourg University Hospital, Strasbourg, France

Background: Respiratory involvement in rheumatoid arthritis (RA) is the most common extra-articular localisation, affecting $50 \%$ of patients, even though only $5 \%$ become symptomatic. Lung pathology as RA related interstitial lung disease is associated with significant morbidity and mortality. Involvement of the respiratory system seems frequent but remains underestimated because of the absence of guidelines about its detection in patients with RA

Objectives: This study aimed at determining the prevalence of respiratory involvement among symptomatic and asymptomatic patients with rheumatoid arthritis managed in a university hospital.

Methods: We conducted a prospective observational study from May 2017 to January 2018 at the Strasbourg University Hospital. The patients included were over 18 years of age, had rheumatoid arthritis according to the ACR/EULAR 2010 criteria and signed informed consent. They responded to a self-administered questionnaire about their medical history, cardiorespiratory symptoms and lifestyle. Epidemiological, clinical and radiological data were assessed. All of the patients had a chest computed tomography $(\mathrm{CT})$ and respiratory function tests (RFT). A collection of salivary flow and a test of Shirmer were carried out, to investigate the presence of a sicca syndrome. Chest CTs were interpreted by a radiologist specialised in lung area.

Results: We included 102 successive patients, 73 women and 29 men. The average disease duration was 34 years. 60 patients were seropositive for rheumatoid factor and 68 for anti-CCP. 59 patients had bone erosions. The average disease activity score (DAS28-CRP) at inclusion was 3.5. 49 patients had associated Sjogren's syndrome. 22 were active smoker. 43 patients were taking long-term corticosteroid therapy. 96 patients were treated with conventional DMARD treatment, 28 with anti-TNF alpha therapy, 16 with Tocilizumab, 12 with Abatacept, 2 with JAK selective inhibitor, and 16 patients were under Rituximab.

Of the 87 RFT performed, 39 were abnormal: 14 reported an obstructive syndrome, 8 a restrictive syndrome, 32 peripheral expiratory braking, suggestive sign of bronchiolitis, and 24 a decrease in the DLCO.

Of the 91 chest CTs, 42 revealed lung nodules (42\%), 15 of which were more than $6 \mathrm{~mm} ; 29$ interstitial syndrome (29\%), among which 5 were non-specific interstitial pneumonitis (PINS), 3 common interstitial pneumonitis (PIC), and the other were non specific interstitial syndrome. 2 chest CT showed pleural effusion and 1 pericarditis. 44 patients had coronary calcifications, among whom 32 had no lipid-lowering therapy.

Conclusions: Pulmonary systemic assessment of RA patients show high prevalence of respiratory involvement: $42 \%$ of patients had lung nodules and $29 \%$ had an interstitial syndrome. Detection of interstitial lung disease may raise questions about RA treatment such as anti-TNF alpha therapy. Rheumatologist should be more aware of respiratory involvement in RA patients and RFT, a non-invasive test, might be useful at diagnosis and follow-up. 